\title{
correspondence
}

\section{Irrationalism and science}

SIR,- - It is no longer surprising to find scientists consulting the stars or the I Ching to help make decisions, but it is nonetheless depressing. It is a sign of the times-a pandemic disillusionment with political and social institutions, with the past, present and even the future. In its wake, rationalism hides defensively in a few remaining outposts, while mysticism strides about in its various forms, pointing accusing fingers at the anti-human, anti-God, anti-fun, anti-truth, anti-soul, anti-life of science and rationality. Like all trends, irrationalism is not new, but the speed at which it has come upon us this time around and its proportions are a little frightening.

Uri Geller is a case in point. Ten years ago he would have been a charismatic illusionist; today he is a cult figure, believed by many to have various super-human powers normally reserved for Gods and comic-strip heroes. Scientists join him on television programmes and assure us that his feats cannot be explained by present-day science, neglecting the possibility that they may be best understood in the context of present-day magic. That television, radio and newspaper science journalists should join, or even lead the parade of the occult is perhaps not surprising, but that a prestigious scientific journal like Nature should be a credulous participant is a disquieting indication of how far irrationalism has invaded our profession. By acclaiming Geller an important "challenge to scientists" (Nature, 246, 321; 1973) and by publishing an inadequately controlled study on Geller's performance at the Stanford Research Institute (Nature, 252, 559; 1974), Nature has added its prestige to irrationalism and given it a coveted stamp of scientific approval. Rather than making exceptions and lowering standards in order to publish papers of this kind, surely scientists, and the journals that represent them, have a responsibility to themselves, to science and to society to defend the rational approach against the present wave of obscurantism and anti-reason. Although this will raise cries of "scientific elitism", it is simply recognising the definition of science, and approach does not demand the disclaiming of unusual phenomena as impossible, but rather an objective assessment of the probabilities in explaining them, and excluding all natural explanations before turning to supernatural ones. To do otherwise is irrational. A rational perspective on Uri Geller was provided by the New Scientist (October 17, 1974).

No matter what the explanations for Geller's various feats turn out to be, he has served to point up two wellknown, but often forgotten facts that deserve publicity and further study. People are remarkably inaccurate observers and reporters of events, even when their professions, such as science or journalism, rely heavily on objective reporting. Suggestion can have powerful effects on the thoughts, sensations and behaviour of most people, which can be useful (as in acupuncture anaesthesia), but which also can be dangerous. It is sobering to think what might happen if anyone believed to have Geller-like powers decided to prognosticate on political or economic issues.

University College,

Martin RafF

London, UK

\section{Pacem in maribus}

SIR,-Wendy Barnaby's otherwise fair account of the Pacem in Maribus Convocation (Nature, October 11) gives the impression that I said the "nonconventional" living resources of the ocean-such as squids, krill, lanternfishes-are found mainly in the area beyond the proposed Exclusive Economic Zone. That is not so. The large potential food resources are found both far offshore and rather near coasts. Their geographical distribution is not well known, but the occurrences of high densities are related to zones of high primary productivity. Uncentainty as to jurisdiction over these resources derives less from ignorance of the distributions, than from uncertainty as to the extent of the coastal regime yet to be negotiated. There are many areas of controversy regarding the zonal concept and estimates of the proportion of the total ocean surface which would be under some form of coastal state jurisdiction range from 30 to $90 \%$.

The "unconventional" resource nearest to commercial exploitation is the krill, much of which occurs within 200 miles of the Antarctic continental coastline. With the present Antaratic Treaty in force there would presum- ably be no EEZ claimed there, but some Parties to the Treaty are considering possible revisions to it to facilitate resource exploitation (Science, 184:776-780; 1974). Of the 12 Parties only two are "developing" states. Seven of the remaining ten are affluent northern hemisphere nations, and three of them have active programmes of research and development on krill.

In future either much of the krill resources will be in the waters of the "international zone" or "high seas" or in the coastal zones of a few countries, including perhaps those which successfully lay claim to the Antarctic resources. Similar arguments can be made for ather unconventional resources elsewhere. It may be unwise for the developing countries to assume that the potential living resources of the ocean will lie, as do those resources which are now exploited near to their biological limits, mainly within the jurisdictions of coastal states under an EEZ regime. Further, to which particular types of resources (apart from minerals) such jurisdictions will apply, and under what restraints, remains to be determined, with many difficult questions as yet unresolved.

Royal University of Malta,

S. J. HolT

Msida, Malta

\section{Beware the ghost writer}

SIR,--One may sympathise with Dr Cater (Nature, November 29) who has had his work attributed to Dr Carter but what of the attribution of work to authors who do not exist?

In the journal Cancer $(29,1398 ; 1972)$ appears a paper by T. Ghose and S. P. Nigam but unfortunately one of the qualifications following Professor Ghose's name is given as M.R.C.PATH and is printed in the same fount as the authors' names.

This has confused several writers quoting this paper who have referred to it as being by Ghose, Path, and Nigam.

The phantom Dr Path has unfortunately been given bibliographical clothes by the cancer abstracting journal Excerpta Medica (Cancer Section) $(23$; 1973) who give him an entry in their author index.

Dennis A. Brunning

Chester Beatty Research Institute,

London, UK 